\title{
ENVIRONMENT IMPACT OF A CONCENTRATED SOLAR POWER PLANT
}

\author{
Mladen BOŠNJAKOVIĆ, Vlado TADIJANOVIĆ
}

\begin{abstract}
More recently, there has been an increasing interest in the use of concentrated solar thermal energy for the production of electricity, but also for the use in cogeneration and trigeneration. In this sense, the increasing use of solar thermal energy in urban areas is expected, and its impact on the environment is inducing an increasing interest. The paper analyses the impact of concentrated solar power technology (linear Fresnel, parabolic trough, parabolic dish, and central tower) on the environment in terms of water consumption, land use, wasted heat, emissions of gases, emissions of pollutants that include the leakage of heat transfer fluid through pipelines and tanks, impact on flora and fauna, impact of noise and visual impact. The impact on the environment is different for different concentrated solar power technologies and depends on whether thermal energy storage is included in the plant. Water is mainly used for cooling the system, but also for cleaning the surface of the mirror. To reduce water consumption, other cooling technologies (e.g. air cooling) are being developed. The available data from the literature show large variances depending on the size of the plant, geographic location and applied technology.
\end{abstract}

Keywords: concentrated solar power plant; environment impact

\section{INTRODUCTION}

Solar power production can be achieved in two different ways:

a) by using a photovoltaic technique that enables the conversion of total solar radiation directly into electricity,

b) by applying thermal techniques based on the transformation of solar radiation (direct fraction only) into heat to generate steam used in the turbine as a working fluid, as it is the case with classical thermoelectric power plants.

The basic advantage of the second way is the fact that it is much easier and achievable to store energy in the form of heat at a larger scale than in the form of electricity.

Photovoltaic plants do not provide continuous electricity to the grid causing major network stability risks. Against them, solar thermal power plants can provide $24 \mathrm{~h}$ /day of very stable power to the grid thanks to large heat storages they use when there is no solar energy.

The commercial deployment of Concentrated Solar Plants (CSP) started in 1984 in the United States. From 2005 to 2016, electricity production from CSP plants increased from $0.04 \mathrm{GWh}$ to $11.9 \mathrm{GWh}$. The total capacity of CSP plants on the world level was $5133 \mathrm{MW}$ at the end of 2017.

CSP utilizes mirrors to concentrate the sun's radiation onto a receptor through which heat transfer fluid (HTF) is passing. Heat that is absorbed by the fluid is used to produce vapour which, by applying a conventional thermodynamic cycle (usually Rankin's cycle), is converted into electricity using a steam turbine coupled to an electric generator.

There are several types of CSP plants, and most often, they are classified according to the type of the solar collector used. More than $80 \%$ of CSP installed capacity in the world is based on parabolic trough collector technology. However, other types of plants based on linear Fresnel reflectors, central tower and parabolic dishes are also being used [1]. In all CSP parabolic trough plants, conceptual design is very similar, but remarkable differences exist in the plant scale (usually between $20 \mathrm{MWe}$ to $100 \mathrm{MWe}$ ), type of the heat transfer fluid, heat transfer mode between the particular parts of the power plant and other operating conditions.
Additionally, some power plants may have a thermal storage system which allows them to produce electricity after sunset, thus increasing the total production capacity of the plant (Fig. $1)$.

In some cases, an auxiliary boiler can be integrated with natural gas or fuel oil to increase production capacity and increase the overall energy efficiency of the system [3].

All CSP systems can extend the time of solar operation to base load by applying larger collector fields and thermal energy storage. Solar heat absorbed during the daytime can be stored in thermal energy storage systems based on molten salt, concrete, ceramics or phase change materials. At night, thermal energy can be recovered from thermal storage to produce electricity continuously. This is an important feature for use in desalination processes, which typically require a continuous steady-state process and constant energy input the whole day. Furthermore, the CSP unit in combination with the classical boiler unit can be used for electricity and heat co-generation. In this case, the plant achieves efficiency up to $85 \%$. Possible applications include the combined production of process heat, district cooling, and seawater desalination. The trend is also about applying trigeneration. One such prototype small-scale solar trigeneration system was built at Orte near Rome (Italy) to meet the needs for heating, electricity and cooling of residential users [4].

Each made-up facility for energy utilization and conversion affects the environment and individual ecosystems on Earth. Since CSP systems are being built more in Europe in areas outside the desert, it is good to know the potential impacts of these facilities on the environment.

This impact on the environment is different in some aspects for different plants and the following is usually analysed:

- Land used

- Water used

- Gas emission to the atmosphere

- Waste emission and impact on water, soil, and air

- Noise emission

- Visual impact. 


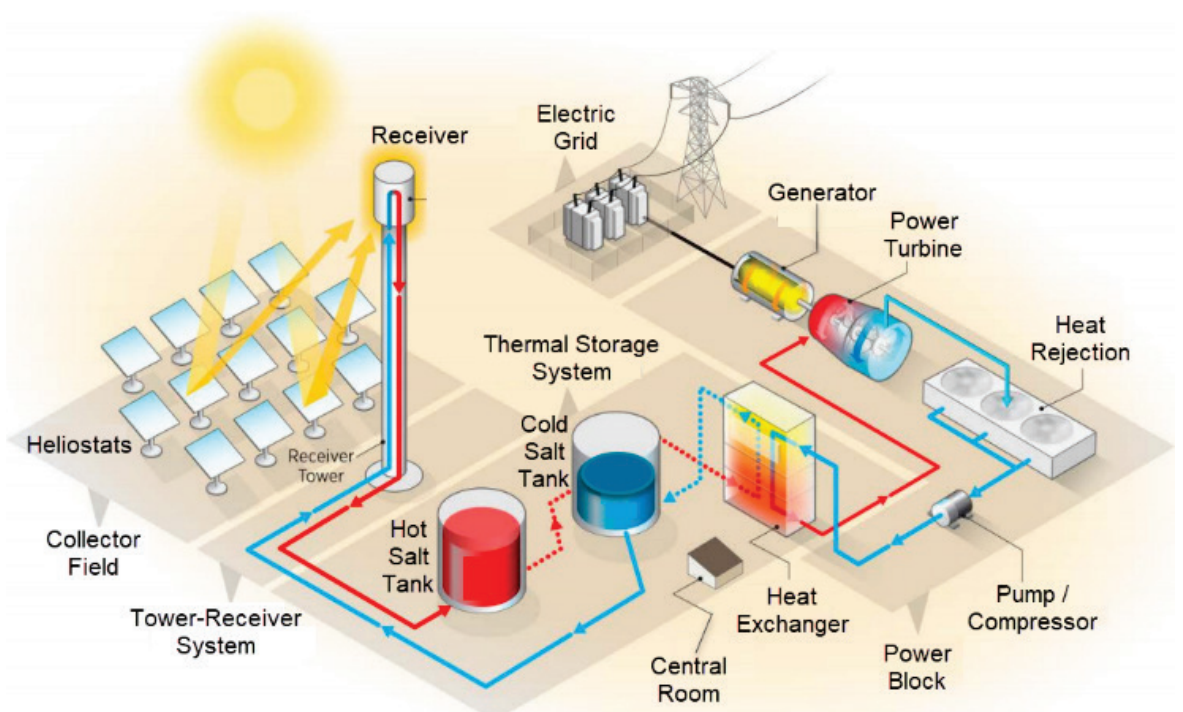

Figure 1 Power tower with direct storage of molten salt. Today's and advanced molten salt projects are conceptually similar, but higher salt temperatures are expected with the $\mathrm{sCO}_{2}$-Brayton energy cycle [2]

\section{THE POTENTIAL ENVIRONMENTAL IMPACT}

Studies usually evaluate the life-cycle environmental impacts of CSP plants. The life-cycle analysis (LCA) defines boundary conditions to include processes, such as manufacturing (extraction of raw materials, transport to the factory, component manufacturing processes, transportation to the regional warehouse), construction (land preparation, construction of auxiliary facilities, plant assembly), operation, and maintenance (production of spare parts and their transportation to the site, fuel consumption of maintenance vehicles, water consumption for mirror cleaning), dismantling (energy required to disassemble plant components) and disposal (energy required for transporting waste to landfills, recycling of components, incinerator or the energy required for final disposal).

\subsection{Land Used}

The land use of solar systems depends strongly on the level of insolation. The land used of a given site decreases with higher insolation, which is why the same system may require up to three times more land for high latitudes than for sites closer to the equator. CSP plants globally require a significant amount of land that must be relatively flat.

There are different metrics for evaluating land-use impacts. Two metrics are most often applied for land use. The first metrics is the total surface area, which corresponds to all land enclosed by the site boundary. The boundaries of the site where the power plant is located are usually specified in blueprint drawings and are usually protected by a fence.

Another metric is the area occupied by individual plant components which comprise land directly occupied by solar arrays, substations, service buildings, access roads, and other infrastructure. This direct-impact area is contained within the total-area border and is smaller than the total area.

Land use is quantified on a basis of capacity (area/MWel) and generation (area/GWh/yr). Capacity-based results are useful for judge land-use and new projects costs, because power plants are often rated in terms of capacity. Results based on generation provide a more consistent comparison between technologies that differ in the capacity factor and enable the evaluation of land-use impacts that vary by solar irradiation, storage options, the way of tracking and applied technology [5].

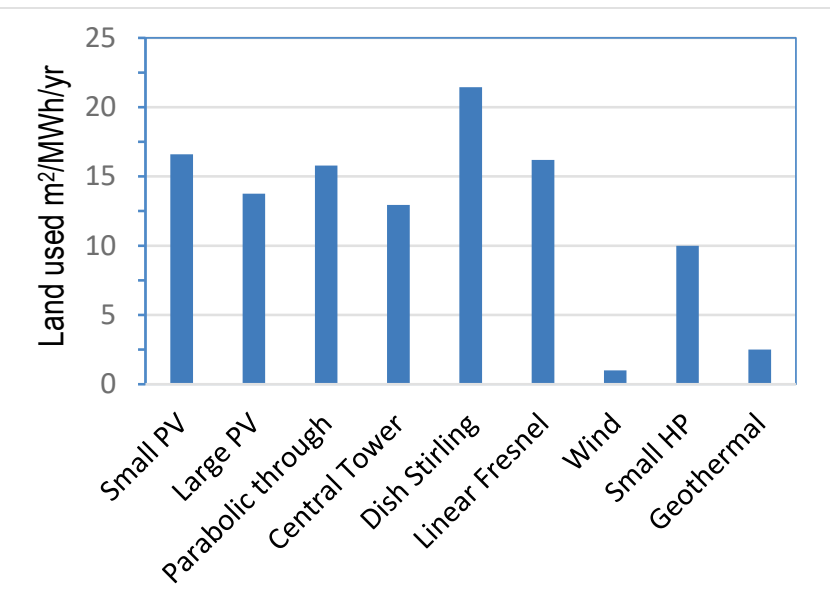

Figure 2 Land used of different technologies [5]

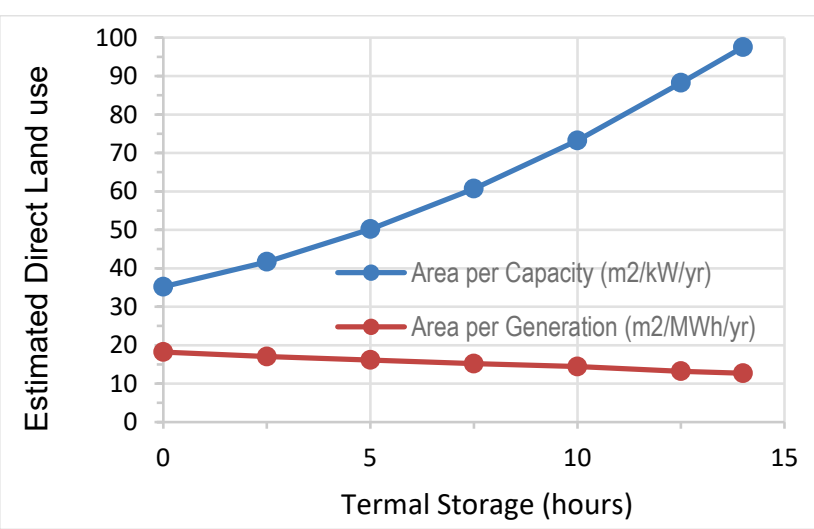

Figure 3 The relationship between CSP thermal storage and direct land-use [6] 
Since more recently, more solar power plants have a thermal energy reservoir. In this case, the required surface area increases with the capacity of the reservoir (Fig. 3).

Generally, the land used is higher than for wind power, geothermal power plants, and nuclear power, but lower than for coal, biomass, and hydropower. In the future, growing global energy demand will lead towards lower-quality and open-pit coal mining and oil and gas extraction, using secondary and tertiary recovery technologies (e.g. tight oil and shale gas). This means that the land footprint of nonrenewable energy sources will increase over time, while renewable energy sources can be expected to decrease the land footprint.

\subsection{Water Use and Consumption}

Like other power plants, solar thermal plants have a fairly large water footprint to produce electricity. One part of water is used to produce steam in the thermodynamic cycle, and most of the water ( $85 \%$ to $95 \%$ ) is intended for cooling. The applied cooling technology largely determines the amount of water the plant has withdrawn. Most of the applied cooling water is returned to the environment, but the quality of that water differs from those taken from the environment and that can be a source of concern.

The consumption of a solar power plant with (oncethrough) wet cooling is estimated at up to $3.8 \mathrm{~m}^{3} / \mathrm{MWh}$ of electricity, which is more than the amount of coal (3.123 $\mathrm{m}^{3} / \mathrm{MWh}$ ) and the amount of a nuclear power plant (3.055 $\mathrm{m}^{3} / \mathrm{MWh}$ ) with the same cooling system; but also for gas turbine combined cycle which has the lowest water withdrawal among thermal power plants $(0.57$ to 1.10 $\mathrm{m}^{3} / \mathrm{MWh}$ ) using a wet cooling tower (Fig. 4) $[7,8]$.

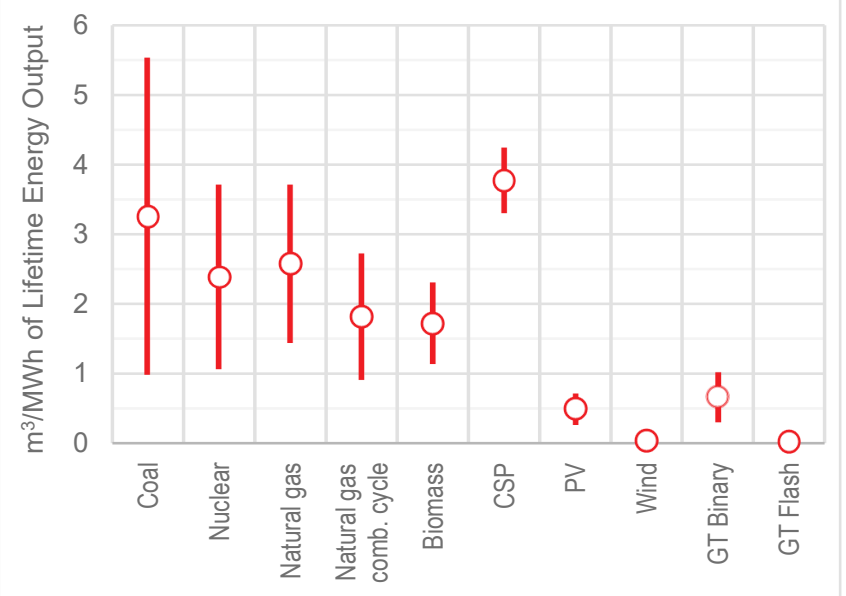

Figure 4 Life-cycle water consumption for power generation $[7,8]$

Water is also used to clean mirrors to maintain high surface reflectivity, although water consumption for this purpose is usually hundreds of times lower than for cooling (around 20 litres/MWh). This water consumption is greater in areas where the wind carries dust particles (deserts), hence the surface fouling is larger. Burkhardt et al. [7] present the most comprehensive life cycle assessment of CSP water consumption, showing that solar thermal power plants with a dry cooling system can reduce the life-cycle water consumption of a parabolic through the plant with TES by $80 \%$. However, water savings also include significant compromises. Capital costs are roughly $10 \%$ higher and power consumption is up to $1.5 \%$ more than for wet cooling plants.

Some studies point out that the change from wet to dry cooling in a $100 \mathrm{MW}$ parabolic trough a CSP plant can decrease the water consumption from $3.60 \mathrm{~m}^{3} / \mathrm{MWh}$ to 0.25 $\mathrm{m}^{3} / \mathrm{MWh}$. However, the application of dry cooling instead of wet increases investment costs and lowers plant efficiency, adding $3.0 \%$ to $7.5 \%$ to the levelled electricity cost. Moreover, this increases LC GHG emissions and the Cumulative Energy Demand (CED) by $8 \%$. Additionally, dry-cooling technology is less effective at environment temperatures above $38{ }^{\circ} \mathrm{C}$. Finally, there are also CSP designs with small freshwater requirements, such as parabolic dishes with Stirling engines and gas turbine towers.

\subsection{Waste}

\subsubsection{Solid and Non-Hazardous Waste}

During the life-cycle of the CSP plant, both maintenance activities and the disposal of waste typical of electricity production will be carried out. Power plant waste includes oily rags, empty containers, broken and rusted metal and machine parts, waste electrical materials and other various solid wastes including the typical waste produced by workers. This waste is classified and managed by a local company authorized to do so. The collection and disposal of waste are carried out in accordance with the appropriate regulatory requirements in order to minimise the safety and health effects.

\subsubsection{Hazardous Waste}

Different hazardous waste can occur during the operation of a power plant. That waste include waste HTF and solvents, waste oil and oil filters, cleaning rags, used or expired deadline of chemicals from the water treatment system, expired deadline of paints, etc. This hazardous waste is temporarily stored on site in appropriate tanks and is permanently disposed of in the appropriate prescribed manner in accordance with the legal regulations. Workers will be trained to handle all hazardous waste generated in the place.

\subsection{Gases Emitted Into the Atmosphere}

The US National Renewable Energy Laboratory (NREL) has conducted a comprehensive LCA of renewable energy sources including the CSP technology [9]. In this life-cycle assessment, 42 GHG emissions were identified in thirteen unique references for Fresnel, parabolic trough, power tower, and parabolic dish technologies. Fig. 5 shows the distributions of the published assessment of life-cycle GHG emissions. Although most published estimates of greenhouse gas emissions in the life-cycle range between $14 \mathrm{~g}$ and $32 \mathrm{~g}$ 
$\mathrm{CO}_{2}$ eq. $/ \mathrm{kWh}$, there are also some discrepancies that can be seen in Fig. 5, as the analysis also covers solar plants that additionally burn natural gas to generate electricity. These are actually hybrid solar power plants [10].

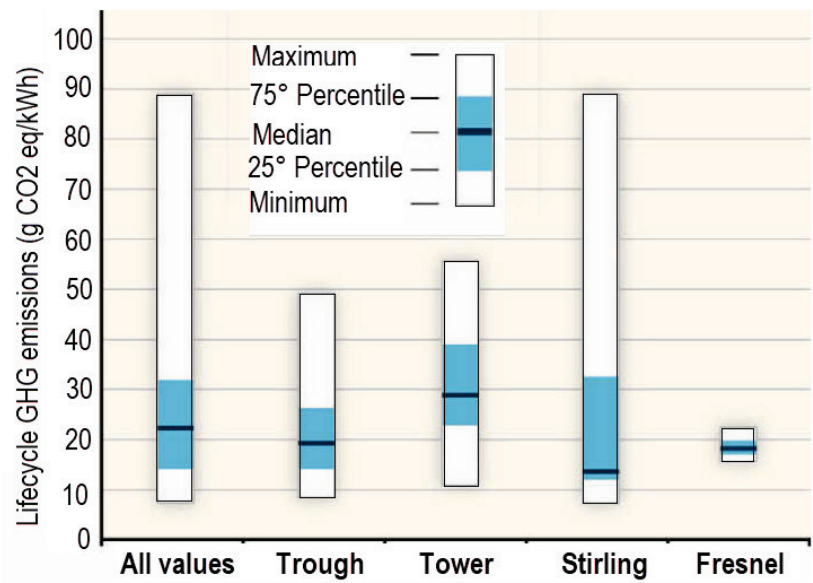

Figure 5 Life-cycle GHG emissions ( $\mathrm{g} \mathrm{CO}_{2}$-eq/kWh) of CSP technologies [10]

Phase Extraction and Component Manufacturing takes $12.97 \%$ of the total $\mathrm{CO}_{2}$ production, the construction phase takes $0.02 \%$, the highest $\mathrm{CO}_{2}$ production is $86.5 \%$ in the plant phase, and dismantling and disposal takes $0.51 \%$.

The production of mirrors and galvanized steel contributes to the majority of greenhouse gas emissions associated with the production of solar field components.

The analysis carried out by Kommalapati et al. [11] also includes a large number of plants. The analysis gives results that are twice as high as those previously presented. However, the relative relationship between different technologies is the same, which means that the parabolic dish (Stirling) has the smallest $\mathrm{CO}_{2}$ emission.

The LCA results also show that plants with TES have approximately twice the life-cycle GHG emissions of the configuration with minimal backup. Plants with dry cooling had slightly higher GHG emissions (5\% to $7 \%$ ) than wetcooled power plants due to the efficiency penalty of internal fan power consumption.

If the heat transfer system uses nitrogen salts, the plant emits nitrogen oxide $\left(\mathrm{N}_{2} \mathrm{O}\right)$ into the environment. The emission of this gas is extremely small compared to the carbon dioxide emissions from fossil fuels, but it is certainly not negligible because nitrogen oxide is a stronger greenhouse gas than carbon dioxide and it is necessary to control and solve this problem.

\subsection{Wasted Heat}

All heat energy-converting systems produce waste heat that can have a significant share (Fig. 6). This applies to CSP generation as well. The waste heat fraction depends on the applied technology.

As seen from Fig. 6, the waste heat in the CSP plant is smaller than for geothermal plants and power plants on natural gas, but it is higher in relation to coal-fired and oilfired power plants.

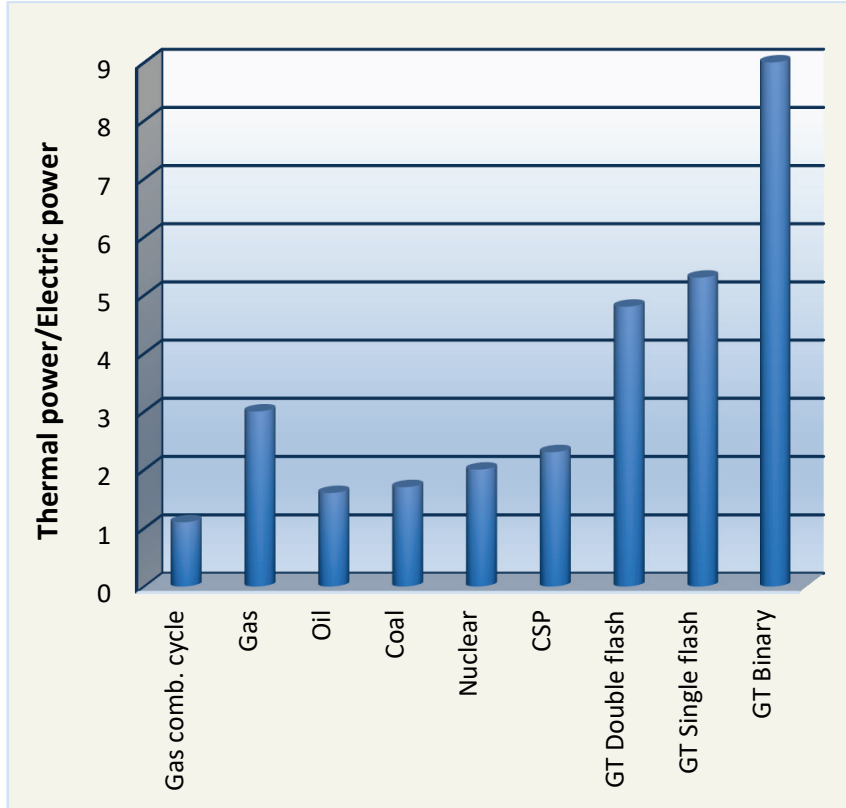

Figure 6 Waste heat (MWt) per unit of electric capacity (MWe) for different processes of power generation [12]

Recently, it became very popular to utilize waste heat in various ways. One application where the heat from CSP could be used is desalinization. This is particularly important for regions with high irradiation that are suitable for CSPs and are faced with a serious deficit of fresh water. Scientists find that in a co-generation plant, where CSPs apply supercritical carbon dioxide cycle, the power cycle could be combined with thermal desalination using waste heat. The desalination process uses only the waste heat because the s$\mathrm{CO}_{2}$ cycle rejects heat at $70{ }^{\circ} \mathrm{C}$, the temperature required to integrate with the desalination system.

Additional opportunities for wasted heat use may exist in the industrial sector to meet either the heating needs or cooling purposes.

\subsection{Heat Transfer Fluids, Emissions to Soil and Water}

The influence of HTF is manifested in the leaking or emitting into the soil, groundwater and surface water, air and human presence. Linear Fresnel, parabolic trough and parabolic dish technologies have a large number of collectors in the solar fields connected by pipelines that contain HTF and therefore occupy a large area. That large part of the surface is under the potential influence of HTF leakage. This fact indicates that the use of HTFs can be dangerous for the environment.

Small leakage (mainly due to evaporation) and accidental spillage may occur at the plant, so effective protection measures should be organized. Leaking not only affects the environment but also the health of people.

Because of this, people must be trained for possible accidents to minimize the impact on nature and humans and all the necessary protective equipment and equipment must be provided.

This aspect is less problematic for the area of heat storage and the area of process equipment due to small area 
occupancy. In this case, the inspection surfaces are more accessible and it is possible to place protective surfaces against the ground to prevent significant groundwater contamination if HTF or Heat Storage Media (HSM) is leaking. The central tower system is considered as the middle case, whereby the height of the tower can facilitate dispersion on the large area around the tower. Accidental leakage can occur during HTF circulation in some areas that are not protected by insulation, e.g. the central receiver.

If the CSP plant is placed in a populated place, e.g. on the roof of a building and serves for cogeneration or trigeneration, special attention must be paid to HTF.

\subsubsection{Synthetic Oil}

Parabolic trough power plants in Spain and California show some leakages of the synthetic oil used in the receiver. The leakage indicator is in the characteristic smell of HTF. Leaks are reduced by new connection elements (ball joints), while soil pollution is recovered by microbial remediation or by removing and replacing large amounts of soil. In areas with surface ponds or shallow groundwater, synthetic oil contaminates the soil and penetrates very quickly in the water to which it is very poisonous. This fact suggests that synthetic oil should be prohibited in the area of very vulnerable aquifers.

\subsubsection{Alternative HTFs}

HTFs for high-temperature areas have high priority in global research [13]. The results of the research in the past years have led to new systems that do not require synthetic oil, but directly use water/steam as HTF, such as DSG (direct steam production), gases or molten salt mixtures in direct/indirect systems.

Besides the environmental safeguard, the choice of the HTF has various constraints: performances, costs, and plant efficiency. This requires a compromise to meet quality solutions.

Other options involve advanced HTFs, including:

- Pressurised gas, currently under testing

- Systems where molten salt is directly used in solar collectors and energy storage systems, e.g. in a demo plant in Archimedes, Italy

- Use of dense gas-particle suspensions (approximately $50 \%$ of solid) in tubes as HTF. This HTF behaves as a liquid with a wide operating temperature range. It remains in a liquid state at almost any temperature (does not freeze) and allows a working temperature increase up to $700{ }^{\circ} \mathrm{C}$ and above.

- Adding nanoparticles to the above-mentioned fluids will result in nanofluids that greatly enhance physical and transport properties and have a positive impact on the environment.

- Use of special additives in order to reduce the melting point for molten salt mixtures. The nitrate salts $\mathrm{NaNO}_{3}$ and $\mathrm{KNO}_{3}$ of the TES are mainly (at about $60 \%$ ) natural products mined in northern Chile, and the rest are from the chemical industry. Even if the main part of this salt is a natural mineral material, it leaves a significant environmental footprint due to energy consumed for mine extraction, transportation, salt processing and application in TES [14].

\subsection{Materials in CSP Plants}

CSP plants use a lot of working materials inside their system, far more than the conventional fossil fuel power plants. The main materials used are most often steel, glass, and concrete with a relatively high recycling rate, typically over $95 \%$. Materials that cannot be recycled are mostly inert and can be used for road building or can be land-filled safely. However, there are several toxic materials (compounds) found within the CSP system, most often synthetic organic compounds such as biphenyls and biphenyl ether used in the heat transfer system. These compounds can cause a fire and may, during leakage in the system, reach the ground through which they can reach other parts of the environment and need to be treated as hazardous waste. From the soil, poisonous compounds can be absorbed by plants, and by eating these plants, animals can also absorb them. One of the ways in which they try to solve toxic materials is by replacing them with water or molten salts.

\subsection{Impacts on Flora and Fauna}

Impacts of CSP plants on the local environment may be associated with creating access roads, building works, and ecosystem disturbance. Construction of facilities, roads and car parks causes the destruction of the local fauna. The extent of destruction depends on the area affected and the type of land use before the construction of the plant.

Construction of the plant can lead to fragmentation of the habitat, which means that species lose the optimal integrity of the ecosystem for their survival. The power plant uses environmental resources (water), thereby reducing the resources necessary for the plants and animals that live there. In Mediterranean areas, plants that are drowned due to lack of water can also contribute to the risk of fire over plants directly affect the vertebral mortality in two ways: collision with the upper parts of the plant (especially with the central tower) and heat stroke or combustion of the surrounding area resulting from the reflection of concentrated solar radiation [15]. Birds rarely collide with the tower of the plant when the visibility is good, but with reduced visibility, a greater number of dead birds have been recorded. Birds can also replace reflective water surface mirrors and, when being convinced of diving into the water, collide with them and become injured. During the operational phase it was noted that the plant and animal world gradually adapt to the new environment. For example, some dwarves are trying to build a nest on the heliostat, and the turkeys returned and feed in the vegetation of the heliostat field.

Building power plants may be a barrier to migratory pathways to local plant and animal populations and thus their chances of survival may be reduced. Likewise, there may be an increase in the number of invasive species to that area. When transporting equipment and materials for the 
construction of a plant, the site can be introduced to invasive alien species or species whose natural habitat is not in this ecosystem. Invasive foreign species often have the ability to rapidly propagate and spread and then pose a major threat to domestic species.

Collector arrays in CSP plants affect the profile of wind flow. The mean wind speed is drastically reduced, and the kinetic energy of turbulence grows within the collector field. Reducing wind speed is of great benefit because speed is of primary importance for the desert spread. That is, the collector field acts beneficially in soil protection from erosion.

The collector field in CSP plants also has an influence on the soil temperature below the collector. Depending on where the plant is built, the temperature of the soil in winter may be several ${ }^{\circ} \mathrm{C}$ higher and during the spring and summer several ${ }^{\circ} \mathrm{C}$ lower than the soil temperature outside the collector field (according investigation of Zhiyong $\mathrm{Wu}$ et al. [16] in Yanqing, China, temperature difference was from $0.5^{\circ} \mathrm{C}$ to $\left.4{ }^{\circ} \mathrm{C}\right)$.

\subsection{Potential Noise Sources}

Noise from the solar power plant is not significant compared to other types of power plants, such as conventional coal, wind power generation, and gas turbine power plants. The noise from the generating plant of the large-scale trough, Fresnel and power tower plants is unlikely to cause any disturbance to the public since the power block is invariably located at the centre of a large solar field, far from the facility boundary. The effects of noise are greater in the construction phase of the plant, but this impact can be mitigated with the adoption of good work practices. According to the items listed below, the noise is generated in the operation of the plant due to:

- Boiler start-up and operating noises

- Salt and water pumps

- Cooling fans

- Stirling engines

- Waste Water Treatment operations

- Service vehicles (for cleaning mirrors)

- Power transformer noises and

- Transmission line noises.

In the variant of the use of CSP cogeneration and trigger systems, collectors can be placed on the roofs of buildings or factory halls. For this case of CSP application, noise can, though not large, potentially pose a problem for the tenants of the building.

\subsection{Visual Intrusion}

It is very important to carefully select the location of the solar thermal power plant, as this will be closely related to the visual impact. Due to specific operating requirements of these types of systems, CSP plants are typically placed in regions with a small demographic density and very small visual impact may be introduced as far as natural reserves are avoided. The solar tower system makes a higher visual impact than technologies such as the parabolic trough, dish Stirling and Fresnel, due to the height of the central tower. In terms of new trends in the use of CSP cogeneration and trigeneration systems, collectors can be placed on the roofs of buildings. In this case, the CSP system have a significant visual impact.

\section{CONCLUSION}

There are different factors that influence the CSP environmental profile, including location, size, applied technology and materials (for construction, HTF, etc.), water use, land use, operation and maintenance needs, etc.

Despite the fact that this kind of power plant has a negative impact on the environment, it is obvious that CSP plants have much better ecological performance than today's fossil power plants. Since they do not use any fuels, there are no oil spillage or methane leaks. On the other hand, the use of materials such as concrete, steel, and glass means the possibility of their recycling.

The problems that need to be solved are the water demand in the dry areas, the use of toxic synthetic oils as a heat transfer fluid and the use of pesticides to limit the growth of vegetation in heliostat fields. For all these problems, there are technical solutions or they are in the development phase.

The impacts of certain applied technologies on the environment are different. Although some CSP technologies are commercialized, they are less mature than conventional fossil fuel power plants. Due to the great interest in this area and the increasing number of research, significant improvements in the efficiency of these systems can be expected, with less environmental impact.

As far as CSPs are concerned, there is a need for further research into Stirling's systems, the effects of storage materials on the ecological profile of the entire CSP plant, water-saving strategies in the cooling system, the application of the Brayton cycle and the application of hybrid solar power plants.

\section{REFERENCES}

[1] Palgrave, R. (2008). Innovation in CSP. Renewable Energy Focus, 9(6), 44-49. https://doi.org/10.1016/S1755-0084(08)70066-8

[2] Mehos, M. at al. (2017). Concentrating Solar Power Gen3 Demonstration Roadmap, Technical Report NREL/TP-550067464. https://www.nrel.gov/docs/fy17osti/67464.pdf

[3] Giostri, A., Binotti, M., Astolfi, M., Silva, P., Macchi, E., Manzolini, G. (2012). Comparison of different solar plants based on parabolic trough technology, Solar Energy, 86 (5) 1208-1221. https://doi.org/10.1016/j.solener.2012.01.014

[4] Cioccolanti, L., Villarini, M., Tascioni, R., \& Bocci, E. (2017). Performance assessment of a solar trigeneration system for residential applications by means of a modeling study. Energy Procedia, 126, 445-452. https://doi.org/10.1016/j.egypro.2017.08.211

[5] Ong, S., Campbell, C., Denholm, P., Margolis, R., \& Heath, G. (2013). Land-Use Requirements for Solar Power Plants in the United States, Technical Report NREL/TP-6A20-56290

[6] Turchi, C., Mehos, M., Ho, C., \& Kolb, G. (2010). Current and Future Costs for Parabolic Trough and Power Tower Systems 
in the US Market. NREL/CP-5500-49303. Golden, CO: National Renewable Energy Laboratory.

[7] Burkhardt, J. J., Heath, G. A., \& Turchi, C. S. (2011). Life Cycle Assessment of a Parabolic Trough Concentrating Solar Power Plant and the Impacts of Key Design Alternatives. Environmental Science \& Technology, 45(6), 2457-2464. https://doi.org/10.1021/es1033266

[8] Cho, A. (2010). Energy's tricky tradeoffs. Science, 329 (5993), 786-787. https://doi.org/10.1126/science.329.5993.786

[9] Burkhardt, J. J., Heath, G., \& Cohen, E. (2012). Life Cycle Greenhouse Gas Emissions of Trough and Tower Concentrating Solar Power Electricity Generation. Journal of Industrial Ecology, 16, S93-S109. https://doi.org/10.1111/j.1530-9290.2012.00474.x

[10] Arvizu, D. P., Balaya, L., Cabeza, T., Hollands, A., JägerWaldau, M., Kondo, C., Konseibo, V., Meleshko, W., Stein, Y., Tamaura, H., \& Xu, R. Z. (2011). In IPCC Special Report on Renewable Energy Sources and Climate Change Mitigation Cambridge, United Kingdom and New York, NY, USA: Cambridge University Press.

[11] Kommalapati, R., Kadiyala, A., Shahriar, M., \& Huque, Z. (2017). Review of the Life Cycle Greenhouse Gas Emissions from Different Photovoltaic and Concentrating Solar Power Electricity Generation Systems. Energies, 10(3), 350. MDPI AG. https://doi.org/10.3390/en10030350

[12] Rybach, L. (2005). Environmental Aspects of Geothermal Energy Development and Utilisation and Related Legal, Institutional and Social Implications. World Geothermal Congress (WGC 2005). Pre and Post Congress Short Courses. Izmir and Antalya, Turkey, April 2005.

[13] Srivastva, U., Malhotra, R. K., \& Kaushik, S. C. (2015). Recent Developments in Heat Transfer Fluids Used for Solar Thermal Energy Applications. Journal of Fundamentals of Renewable Energy and Application, 5, 189. https://doi.org/10.4172/2090-4541.1000189

[14] Py, X., Sadiki, N., Olives, R., Goetz, V., \& Falcoz, Q. (2017). Thermal energy storage for CSP (Concentrating Solar Power). The European Physical Journal Conferences, 148, 00014. https://doi.org/10.1051/epjconf/201714800014

[15] Hernandez, R. R., Easter, S. B., Murphy-Mariscal, M. L., Maestre, F. T., Tavassoli, M., Allen, E. B., Barrows, C. W., Belnap, J., Ochoa-Hueso, R., Ravi, S., \& Allen, M. F. (2014). Environmental impacts of utility-scale solar energy. Renewable and Sustainable Energy Reviews, 29, 766-779. https://doi.org/10.1016/j.rser.2013.08.041

[16] Zhiyong, Wu, et al. (2014) Environmental impacts of large scale CSP plants in northwestern China, Environmental Science: Processes and Impacts, 16, 2432-2441. https://doi.org/10.1039/c4em00235k

\author{
Authors' contacts: \\ Mladen BOŠNJAKOVIĆ, PhD, Assistant Professor \\ (Corresponding author) \\ College of Slavonski Brod \\ Dr. Mile Budaka 1 \\ 35000 Slavonski Brod, Croatia \\ mladen.bosnjakovic@vusb.hr \\ Vlado TADIJANOVIĆ \\ Rastušje 42 \\ 35107 Podvinje, Croatia \\ vlado.tadijanovic1@inet.hr
}

